\title{
DNA-Based Sensor for the Detection of an Organophosphorus Pesticide: Profenofos
}

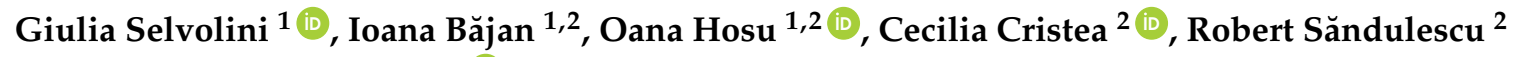 \\ and Giovanna Marrazza 1,3,* (iD) \\ 1 Department of Chemistry "Ugo Schiff”, University of Florence, Via della Lastruccia 3, \\ 50019 Sesto Fiorentino (FI), Italy; giulia.selvolini@unifi.it (G.S.); bajanioana@yahoo.com (I.B.); \\ hosu.oana@umfcluj.ro (O.H.) \\ 2 Department of Analytical Chemistry, University of Medicine and Pharmacy "Iuliu Haţieganu”, 4 Pasteur \\ Street, 400349 Cluj-Napoca, Romania; ccristea@umfcluj.ro (C.C.); rsandulescu@umfcluj.ro (R.S.) \\ 3 Istituto Nazionale Biostrutture e Biosistemi (INBB), Unit of Florence, Viale delle Medaglie d'Oro 305, \\ 00136 Roma, Italy \\ * Correspondence: giovanna.marrazza@unifi.it; Tel.: +39-055-457-3320
}

Received: 8 May 2018; Accepted: 19 June 2018; Published: 25 June 2018

\begin{abstract}
In this work, we propose an electrochemical DNA aptasensor for the detection of profenofos, an organophosphorus pesticide, based on a competitive format and disposable graphite screen-printed electrodes (GSPEs). A thiol-tethered DNA capture probe, which results to be complementary to the chosen aptamer sequence, was immobilised on gold nanoparticles/polyaniline composite film-modified electrodes (AuNPs/PANI/GSPE). Different profenofos solutions containing a fixed amount of the biotinylated DNA aptamer were dropped onto the realized aptasensors. The hybridisation reaction was measured using a streptavidin-alkaline phosphatase enzyme conjugate, which catalyses the hydrolysis of 1-naphthyl -phosphate. The 1-naphtol enzymatic product was detected by means of differential pulse voltammetry (DPV). The aptasensor showed itself to work as a signal off sensor, according to the competitive format used. A dose response curve was obtained between $0.10 \mu \mathrm{M}$ and $10 \mu \mathrm{M}$ with a detection limit of $0.27 \mu \mathrm{M}$.
\end{abstract}

Keywords: screen-printed electrodes; aptasensor; nanoparticles; organophosphorus pesticide; profenofos

\section{Introduction}

"Pesticide" is a term used in a broad sense to address any substance or mixture of substances used to limit the growth of infesting species (e.g., insects, weeds, little mammals, fungi, etc.) that can compromise agricultural production. As stated by the Food and Agriculture Organization (FAO), a pesticide is defined as substances intended to kill or control pests, but, for the present purposes, it also embraces certain materials used to modify the behaviour or physiology of pests (e.g., insect repellents and synergists) or of crops during production or storage (herbicide safeners, germination inhibitors) [1]. Pesticide residues may gain access to the food chain through air, water and soil, which is an outstanding issue to face, since most of the substances used as pesticides are constituted of neurotoxic compounds.

Organophosphorus pesticides (OPs) like phorate, profenofos, and isocarbophos are highly toxic substances that irreversibly inhibit the enzyme acetylcholinesterase, an essential enzyme for the central nervous system to function properly both in humans and insects. This inhibition causes the accumulation of the acetylcholine neurotransmitter in nerves, which affects muscular activities and the normal functioning of vital organs, causing severe symptoms and even death $[2,3]$. Thus, the 
analysis of pesticide residues is an important concern due to their bioaccumulation effect, high toxicity, and long-term damage risk to environment and human health security.

In 2013, the Acceptable Daily Intake (ADI) was established for profenofos as $0-0.03 \mathrm{mg} / \mathrm{kg}$ body weight from the Codex committee, FAO, and WHO. The highest level of a pesticide residue that is legally tolerated in or on food depends on its nature.

To date, the detection and the quantification of the pesticides are generally based on conventional chromatographic techniques coupled with mass spectroscopy [4], which provide sensitive and selective detection. In particular, profenofos have been carried out both through a gas-liquid chromatographic method using a flame-ionization detector [5] and an HPLC-based method using a diode array detector (DAD) [6].

The chromatographic techniques commonly require highly skilled personnel and are not suitable for screening analysis. Thus, biosensor development for pesticide analysis represents a rapid, cost-effective, and easy alternative to conventional techniques for environmental monitoring, including in situ analysis [7]. The main drawback in developing biosensors for detecting pesticides consists in the synthesis of antibodies for these highly toxic targets. In this perspective, the use of bio-mimetic receptors such as DNA aptamers has recently become an interesting alternative, since they have shown themselves as good candidates as recognition elements in more robust and stable biosensors for pesticide detection [8-10].

Recently, some aptamer-based biosensors (aptasensor) have been developed for the determination of OPs. A colorimetric assay was developed employing gold nanoparticles (AuNPs) modified with aptamer for the detection of omethoate. The aptamer showed high selectivity towards omethoate, resulting in the disconnection of aptamer molecules from AuNPs and in their aggregation. Using the OP-binding aptamer and target-induced colour changes in AuNPs, this biosensor showed a good linearity between $0.1 \mu \mathrm{M}$ and $10 \mu \mathrm{M}$, with LOD of $0.1 \mu \mathrm{M}$ [11]. A similar approach was developed for the colorimetric detection of malathion employing aptamer, cationic peptide and unmodified gold nanoparticles. The biosensor was found to be linear in the range of $0.01-0.75 \mathrm{nM}$ with a limit of detection of $1.94 \mathrm{pM}$ [12].

The use of electrochemical platform for aptasensors leads to many advantages such as realization of arrays for multidetections, device miniaturization, and user-friendly and low-cost apparatus.

An electrochemical aptasensor based on copper oxide nanoflowers and single-walled carbon nanotubes nanocomposite for chlorpyrifos detection was developed by Huo et al. A good linearity for chlorpyrifos ranging from $0.1 \mathrm{ng} / \mathrm{mL}$ to $150 \mathrm{ng} / \mathrm{mL}$, with a low detection limit of $70 \mathrm{pg} / \mathrm{mL}$, was obtained [13].

Different optical and photoelectrochemical affinity sensors for profenofos detection, based on molecularly imprinted polymers (MIPs) and calixarenes, have been reported in the literature [14-16].

In this work, we developed, for the first time, an electrochemical DNA aptasensor for profenofos based on a competitive assay format using screen-printed cells (SPCs). SPCs are widely used as electrochemical platform for aptasensors for various advantages such as the simple, rapid, and inexpensive manufacturing process. In addition, their low cost permits the possibility of single use in order to avoid the contamination among the samples.

The DNA aptamer was selected from a library of aptamers, built by SELEX, that proved itself to show one of the highest ability to bind profenofos among other organophosphorus pesticides [17]. A thiol-tethered DNA capture probe, which is complementary to the chosen aptamer sequence, was immobilised on gold nanoparticles/polyaniline composite film (AuNPs/PANI) modified graphite screen-printed electrode surface. Different profenofos solutions containing a fixed amount of the biotinylated DNA aptamer were dropped onto the realised aptasensors. The hybridisation reaction was measured using a streptavidin-alkaline phosphatase enzyme conjugate, which catalyses the hydrolysis of 1-naphthyl-phosphate to 1-naphthol. The enzymatic product was detected by means of differential pulse voltammetry (DPV). The aptasensor showed itself to work as a signal off sensor, 
according to the competitive format used. Finally, preliminary experiments were carried out with fruit juices.

This innovative method combines the portability of screen-printed electrochemical cells and of a computer-controlled instrument to ensure the possibility of a disposable and cost-effective in situ analysis.

\section{Materials and Methods}

\subsection{Chemicals}

Aniline, perchloric acid $\left(\mathrm{HClO}_{4}\right)$, tetrachloroauric acid $\left(\mathrm{HAuCl}_{4}\right)$, sulfuric acid $\left(\mathrm{H}_{2} \mathrm{SO}_{4}\right)$, potassium ferrocyanide $\left(\mathrm{K}_{4}\left[\mathrm{Fe}(\mathrm{CN})_{6}\right]\right)$, potassium ferricyanide $\left(\mathrm{K}_{3}\left[\mathrm{Fe}(\mathrm{CN})_{6}\right]\right)$, DL-dithiothreitol (DTT), 6-mercapto-1-hexanol $(\mathrm{MCH})$, di-sodium hydrogen phosphate $\left(\mathrm{Na}_{2} \mathrm{HPO}_{4}\right)$, sodium di-hydrogen phosphate di-hydrate $\left(\mathrm{NaH}_{2} \mathrm{PO}_{4} \cdot 2 \mathrm{H}_{2} \mathrm{O}\right)$, profenofos, paraoxon, di-ethanolamine (DEA), potassium chloride $(\mathrm{KCl})$, magnesium chloride $\left(\mathrm{MgCl}_{2}\right)$, bovine serum albumin (BSA), streptavidin-alkaline phosphatase enzyme conjugate, 1-naphthyl-phosphate, and $p$-nitrophenyl phosphate were purchased from Sigma-Aldrich (Milan, Italy) at analytical grade. Milli-Q water was used for all preparations.

The DNA sequences were purchased from Eurofins Genomics (Ebersberg, Germany) and are listed below:

- thiol-tethered oligonucleotide complementary sequence (oligo-SH): $5^{\prime}-(\mathrm{SH})-\left(\mathrm{CH}_{2}\right)_{6}-\mathrm{CCG}$ ATC AAG AAT CGC TGC AG-3';

- biotinylated DNA aptamer (apt-BIO): 5'-(biotin)-TEG(triethylene glycol)-AAG CTT GCT TTA TAG CCT GCA GCG ATT CTT GAT CGG AAA AGG CTG AGA GCT ACG C-3’.

Prior to immobilisation, the thiol-modified DNA sequence was treated with dithiothreitol (DTT), purified by elution through NAP-5 columns of Sephadex G-25 DNA grade resin (GE Healthcare, Amersham Place, UK) and then quantified by measuring UV absorption at $260 \mathrm{~nm}$.

The buffer solutions used in this work are

1. $\quad$ storage buffer: $10.0 \mathrm{mM}$ TRIS buffer, $\mathrm{pH}$ 8.0;

2. immobilisation buffer: $0.50 \mathrm{M}$ phosphate buffer, $\mathrm{pH} 7.0$;

3. detection buffer: $0.10 \mathrm{M}$ DEA buffer, $0.10 \mathrm{M} \mathrm{KCl}, 1.0 \mathrm{mM} \mathrm{MgCl}_{2}$, pH 9.6.

\subsection{Apparatus}

UV absorption measurements were carried out through a Varian Cary 100 Bio UVspectrophotometer equipped with a $6+6$ peltier thermostatable multicell holder and built-in temperature probes. The results were analysed with the Thermal application provided in the Cary 100 Bio software suite (Agilent, Cernusco sul Naviglio Milan, Italy). Secondary structures of both the DNA sequences were predicted through the Mfold algorithm [18].

Electrochemical measurements were carried out with a portable potentiostat/galvanostat PalmSens electrochemical analyser (PalmSensGA Houten, The Netherlands), and the results analysed by PSTrace 2.3 software. All the reported potentials refer to the pseudo-reference silver screen-printed electrode and all the measurements were carried out at room temperature.

The aptasensors were realised using screen-printed cells formed by graphite working electrode ( $3 \mathrm{~mm}$ diameter), a silver pseudo-reference electrode and a graphite counter electrode (GSPEs). The screen-printed cells were purchased from EcoBioServices (Florence, Italy).

\subsection{DNA Melting Curve Studies}

The hybridisation reaction between the DNA capture aptamer (apt-BIO) and the selected complementary sequence (oligo-SH) was assessed by recording melting curves. Melting temperatures were obtained as first-order derivative plot of absorbance versus temperature. 
Herein, $100 \mu \mathrm{L}$ of $1.0 \mu \mathrm{M}$ oligonucleotide solutions in immobilisation buffer were placed into quartz microcuvettes $\left(1 \mathrm{~cm}\right.$ path length), and the temperature was increased from $25{ }^{\circ} \mathrm{C}$ to $95{ }^{\circ} \mathrm{C}$ at a constant rate of $1.0^{\circ} \mathrm{C} / \mathrm{min}$ directly inside them through the immersed probe into the sample solutions. At the same time, the absorbance at $260 \mathrm{~nm}$ was monitored at $1 \mathrm{~nm}$ spectral bandwidth. Immobilisation buffer was used as a blank solution. The entity of the interaction between the DNA aptamer and the target pesticide was also investigated in the same conditions.

\subsection{Aptasensor Development}

\subsubsection{GSPEs Surface Modification by Electrodeposition of Polyaniline and Gold Nanoparticles}

The developed DNA aptasensor assay was based on a competitive approach, as reported in Figure 1.

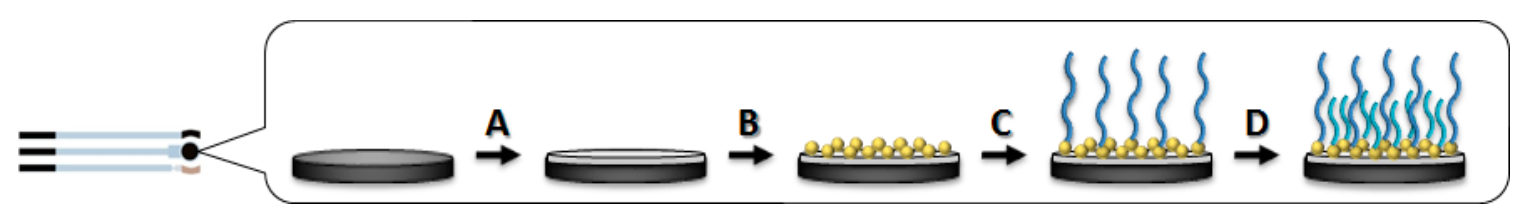

(a)
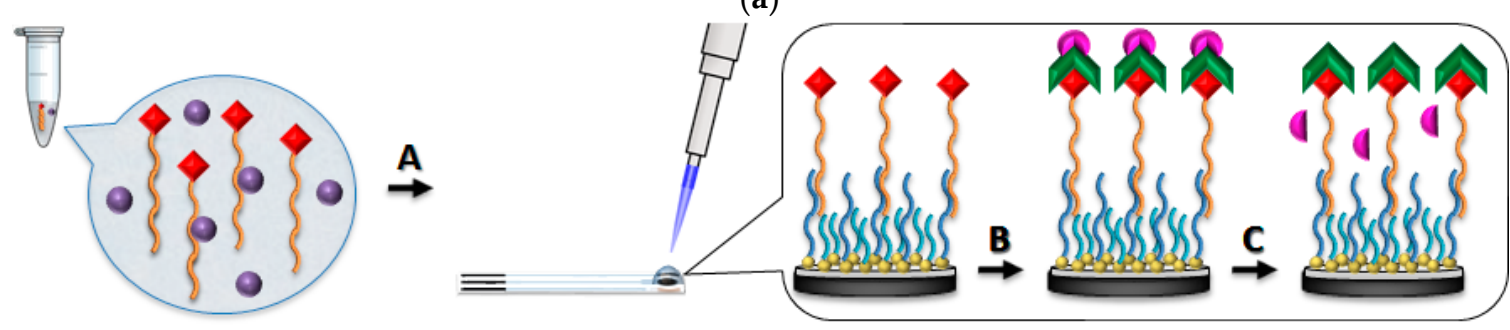

(b)

Figure 1. Scheme of the DNA-based sensor assay for profenofos detection. GSPE surface modification (a) (A) electropolymerisation of polyaniline using $2.5 \mathrm{mM}$ of aniline solution in $50 \mathrm{mM} \mathrm{HClO}$ by cyclic voltammetry (potential range: $-400 \mathrm{mV} \rightarrow+800 \mathrm{mV}$; scan rate: $50 \mathrm{mV} / \mathrm{s} ; 10$ cycles); (B) electrodeposition of gold nanoparticles using $0.5 \mathrm{mM} \mathrm{HAuCl}_{4}$ solution in $0.5 \mathrm{M} \mathrm{H}_{2} \mathrm{SO}_{4}$ by cyclic voltammetry (potential range: $-200 \mathrm{mV} \rightarrow+1200 \mathrm{mV}$; scan rate: $100 \mathrm{mV} / \mathrm{s} ; 15$ cycles); (C) thiolated DNA capture probe immobilisation from $2.0 \mu \mathrm{M}$ solution in $0.50 \mathrm{M}$ phosphate buffer, $\mathrm{pH} 7.0$ (incubation time: overnight); (D) mixed SAM formation with $1.0 \mathrm{mM}$ solution of 6-mercapto-1-hexanol (incubation time: $60 \mathrm{~min}$ ); Hybridisation and detection (b) affinity reaction between profenofos samples and $0.5 \mu \mathrm{M}$ biotinylated aptamer solution (incubation time: $40 \mathrm{~min}$ ); (A) hybridisation reaction between DNA aptamer and immobilised DNA capture probe (incubation time: $30 \mathrm{~min}$ ); (B) coupling with streptavidin-alkaline phosphatase enzyme conjugate $(1.0 \mathrm{U} / \mathrm{mL}$ in $0.10 \mathrm{M}$ DEA buffer, $0.10 \mathrm{M} \mathrm{KCl}$, $1 \mathrm{mM} \mathrm{MgCl}$, $\mathrm{pH}$ 9.6; incubation time: $10 \mathrm{~min}$ ); (C) incubation with $1.0 \mathrm{mg} / \mathrm{mL}$ 1-naphthyl phosphate solution in DEA buffer for $20 \mathrm{~min}$ and electrochemical detection of 1-naphthol by DPV (potential range: $0 \mathrm{mV} \rightarrow+600 \mathrm{mV}$; scan rate: $40 \mathrm{mV} / \mathrm{s}$; step potential: $5 \mathrm{mV}$; modulation amplitude: $70 \mathrm{mV}$ ).

Polyaniline (PANI) and gold nanoparticles (AuNPs) modified GSPEs were realised in accordance with the optimised procedure reported in our previous works [10,19].

Briefly, electropolymerisation of aniline was performed through cyclic voltammetry (CV) by dropping $50 \mu \mathrm{L}$ of $2.5 \mathrm{mM}$ aniline solution in $50 \mathrm{mM} \mathrm{HClO}_{4}$ onto GSPEs. The potential was scanned from $-400 \mathrm{mV}$ to $+800 \mathrm{mV}$ for 10 cycles at $50 \mathrm{mV} / \mathrm{s}$ scan rate.

After washing with $50 \mu \mathrm{L} 0.5 \mathrm{M} \mathrm{H}_{2} \mathrm{SO}_{4}$, AuNPs were deposited through CV by dropping $50 \mu \mathrm{L}$ of $0.5 \mathrm{mM} \mathrm{HAuCl}_{4}$ solution in $0.5 \mathrm{M} \mathrm{H}_{2} \mathrm{SO}_{4}$ onto the polymeric layer. The potential was varied from $-200 \mathrm{mV}$ to $+1200 \mathrm{mV}$ at $100 \mathrm{mV} / \mathrm{s}$ for 15 cycles.

The modified GSPEs were then washed three times with $50 \mu \mathrm{L}$ milli-Q water to remove excess monomer and free ions from the surface. 


\subsubsection{Electrochemical Characterisation of the Modified GSPEs}

Each modification step of the developed platform was electrochemically characterised through CV by dropping $50 \mu \mathrm{L}$ of $5.0 \mathrm{mM}\left[\mathrm{Fe}(\mathrm{CN})_{6}\right]^{3-/ 4-}$ redox probe (equimolar solution in $0.1 \mathrm{M} \mathrm{KCl}$ ) onto the screen-printed cells (SPCs). CV measurements were performed in the potential range from $-500 \mathrm{mV}$ to $+800 \mathrm{mV}$ at $150 \mathrm{mV} / \mathrm{s}$ scan rate. After the electrochemical analysis, the SPCs were discarded.

\subsubsection{DNA Probe Immobilisation}

The nanostructured GSPEs were modified by self-assembly of a mixed monolayer of thiolated DNA capture probe (oligo-SH) and $\mathrm{MCH}$ [20]. The purified thiolated complementary sequence was subjected to a thermal treatment by heating it at $90{ }^{\circ} \mathrm{C}$ for $5 \mathrm{~min}$ and cooling it down to room temperature.

Then, $7.0 \mu \mathrm{L}$ of the $2.0 \mu \mathrm{M}$ capture probe solution were then deposited onto the modified surface of the working electrode and chemisorption was allowed to proceed overnight $(\approx 16 \mathrm{~h})$. During this period, the sensors were stored in petri dishes at $4{ }^{\circ} \mathrm{C}$ to protect the solution from evaporation. To remove unbound oligonucleotide sequences, the surface was washed three times with $15 \mu \mathrm{L}$ of immobilisation buffer.

This immobilisation step was followed by the formation of a self-assembled monolayer (SAM) formation by incubation with $7.0 \mu \mathrm{L}$ of $1.0 \mathrm{mM} \mathrm{MCH}$ aqueous solution for $60 \mathrm{~min}$. Finally, the aptasensors were washed with $15.0 \mu \mathrm{L}$ immobilisation buffer for three times.

\subsubsection{Profenofos Detection}

To obtain a dose-response calibration curve, profenofos detection was performed by dropping a solution containing a proper concentration of biotinylated DNA aptamer (apt-BIO) containing the target pesticide onto the sensor surface and by allowing the competitive reaction to proceed.

In particular, the affinity reaction between $0.50 \mu \mathrm{M}$ biotinylated DNA aptamer and target pesticide in the concentration range $0-10.0 \mu \mathrm{M}$ was first performed into solution; then, after $40 \mathrm{~min}, 7.0 \mu \mathrm{L}$ of these solutions were incubated for other 30 min onto the sensor surface.

The aptasensors were then rinsed for three times with $15.0 \mu \mathrm{L}$ detection buffer.

\subsubsection{Enzymatic Labelling and Electrochemical Measurements}

The biotinylated hybrids formed onto the developed aptasensor surface were further incubated with $15.0 \mu \mathrm{L}$ of a solution containing $1.0 \mathrm{U} / \mathrm{mL}$ of streptavidin-alkaline phosphatase conjugate and $8.0 \mathrm{mg} / \mathrm{mL}$ of BSA in detection buffer. After $10 \mathrm{~min}$, each sensor was washed three times with $100 \mu \mathrm{L}$ detection buffer for two cycles of washings.

Then, after this labelling step, $50.0 \mu \mathrm{L}$ of $1.0 \mathrm{mg} / \mathrm{mL}$ 1-naphthyl-phosphate solution in the detection buffer were placed onto the disposable aptasensors. After $20 \mathrm{~min}$, the electroactive enzymatic product thus formed (1-naphthol) was detected by differential pulse voltammetry (DPV) by scanning the potential from $0 \mathrm{mV}$ to $600 \mathrm{mV}$ at $40 \mathrm{mV} / \mathrm{s}$ (5 mV step potential, $70 \mathrm{mV}$ modulation amplitude) [21].

The current peak height was taken as the electrochemical signal. The signal is expressed in relative percentage units as $S_{x} / S_{0}$ (e.g., ratio between measured signal to blank signal) and plotted versus profenofos concentration. The obtained curve exhibits the typical sigmoidal shape of a competitive assay and was fitted by using OriginPro 8.5 software (OriginLab) with a Boltzmann-type sigmoidal equation [22]:

$$
y=A_{2}+\frac{A_{1}-A_{2}}{1+e^{\left(x-x_{0}\right) / d x}}
$$

where $A_{1}$ is the $y$ value at the top plateau at the curve, $A_{2}$ is the $y$ value at the bottom plateau, $x_{0}$ is the $x$ value at which $y$ is halfway between bottom and top and $d x$ is the slope of the linear part of the curve. 


\section{Results and Discussion}

\subsection{Studies on the Affinity of the DNA Aptamer for the Target Pesticide}

The aptamer was selected from a library of aptamers, built by SELEX that shows the highest ability to bind profenofos among other organophosphorus pesticides. The constant of dissociation was estimated $\mathrm{K}_{\mathrm{d}}=1 \mu \mathrm{M}$ [17]. The selective binding of the analytes is strongly influenced by the secondary structures of the DNA sequences, since aptamers themselves are subjected to conformational changes that create many weak bonds, in order to capture the target molecule. The secondary structures thus formed were predicted by using the MFold algorithm and are shown in Figure 2.

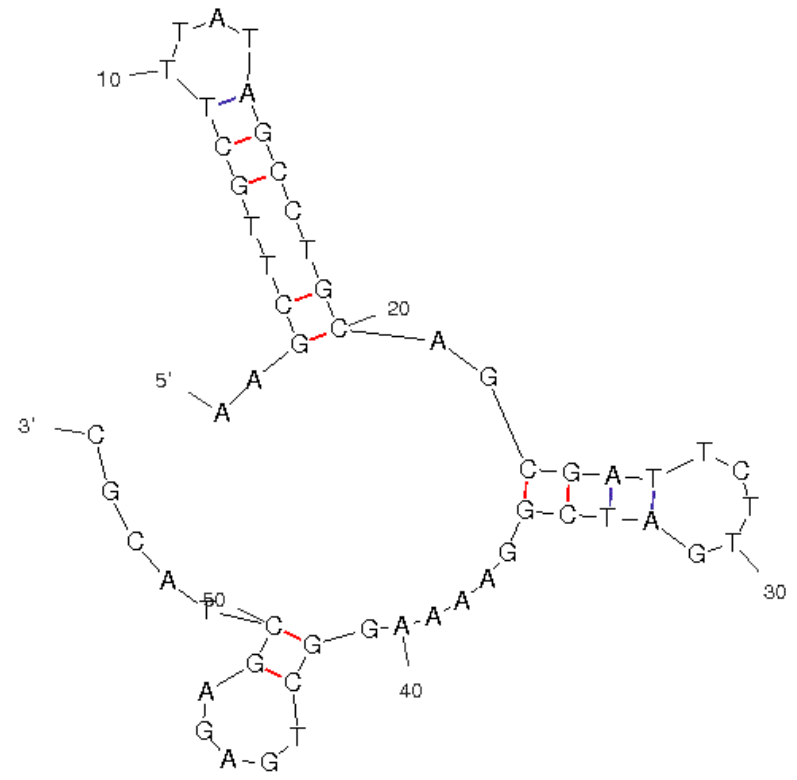

(a)

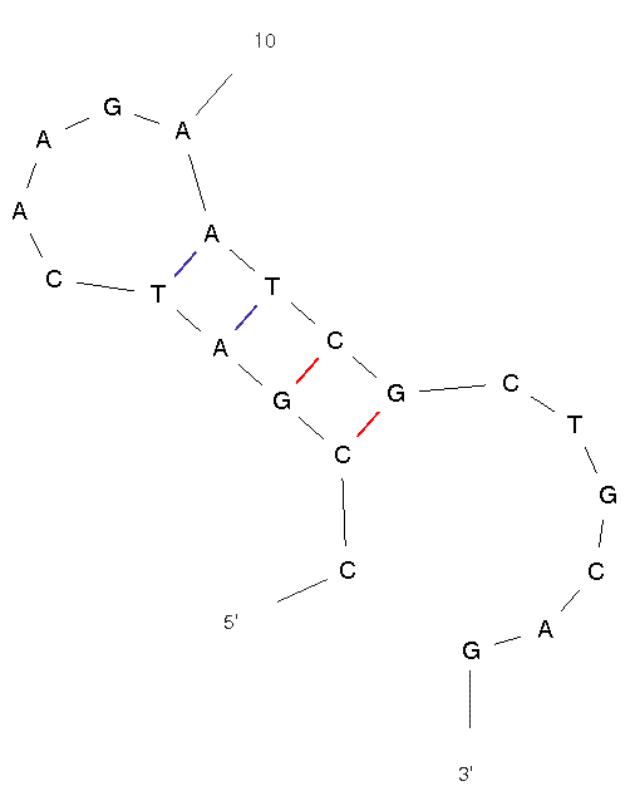

(b)

Figure 2. Secondary structures of apt-BIO (a) and oligo-SH (b) sequences as predicted with the MFold algorithm at $25^{\circ} \mathrm{C}$ in $0.50 \mathrm{M}$ phosphate buffer, $\mathrm{pH} 7.0$, and $0.8 \mathrm{M} \mathrm{Na}^{+}$concentration. The bond between $\mathrm{G}$ and $\mathrm{C}$ is shown in red to indicate its stability.

The prediction temperature was set at $25^{\circ} \mathrm{C}$, and the ionic strength was regulated according to the buffer solution used. The drawing mode was set to untangle with loop fix, while the other parameters were left as default settings. From the predicted conformations, apt-BIO prevalently shows a single-stranded structure characterised by three differently sized loops, while oligo-SH shows a single-loop structure in the same conditions because of its shorter length. For this reason, the hybridisation reaction between the two DNA strands will be more efficient compared to the one that would occur in presence of any other sequence with a more stable secondary structure.

The affinity of the receptor for the analyte and for the chosen complementary sequence was assessed by comparing these structures with preliminary studies on the melting temperatures of the aptamer alone and in presence of its complementary sequence or the pesticide (Table 1).

The obtained $\mathrm{T}_{\mathrm{m}}$ values for the biotinylated aptamer in presence of the thiolated capture probe or profenofos are close to the one related to the aptamer alone; moreover, the overlapping region of the two oligonucleotides is located on the medium-size loop. This suggests that also the interaction with profenofos takes place in the same region. 
Table 1. Melting temperature $\left(\mathrm{T}_{\mathrm{m}}\right)$ values, as obtained from analysing melting curves. The melting curves were performed with $1.0 \mu \mathrm{M}$ biotinylated DNA aptamer (Apt-BIO), $1.0 \mu \mathrm{M}$ thiolated DNA complementary (oligo-SH) and $1.0 \mu \mathrm{M}$ profenofos solutions. The temperature was increased at a constant rate of $1.0^{\circ} \mathrm{C} / \mathrm{min}$ from $25^{\circ} \mathrm{C}$ to $95^{\circ} \mathrm{C}$. Further details are described in the Section 2.3.

\begin{tabular}{cc}
\hline Sample & $\mathbf{T}_{\mathbf{m}}\left({ }^{\circ} \mathbf{C}\right)$ \\
\hline Apt-BIO & 54.0 \\
Apt-BIO + oligo-SH & 58.0 \\
Apt-BIO + profenofos & 57.0 \\
\hline
\end{tabular}

\subsection{Aptasensor Development}

\subsubsection{Modification of GSPEs with Polyaniline and Gold Nanoparticles}

The GSPEs were first modified with a layer of the conducting polymer polyaniline. Since conducting polymers show numerous features suitable for their application in sensing and biosensing (e.g., low cost, flexibility and biocompatibility), they have recently attracted a lot of attention in this field.

Here, the polymer is used to provide higher electroactive area (compared to the bare electrode), protection versus fouling of the electrode surface and scaffold for dispersing and anchoring the metal particles. Inclusion of AuNPs in conductive polymers can enhance electron transfer through a direct or mediated mechanism with improved conductivity and enhanced stability [14]. Further, the AuNPs are an excellent substrate for the immobilisation of thiolated bioreceptor.

The polymerisation profile shows that, for potentials values around $+0.65 \mathrm{~V}$, the formation of the monomer radical decreases with the number of cycles, probably due to the fact that the polymer formed during the first cycles prevents the monomer from reaching the surface of the electrode. Thus, the growth of chains already formed is mainly occurring.

These voltammograms still show, at about $0.14 \mathrm{~V}$ vs. $\mathrm{Ag} / \mathrm{AgCl}$, the redox pair corresponding to the oxidation/reduction of PANI, the peak increasing in height with the number of cycles as the PANI is formed (Figure 3).

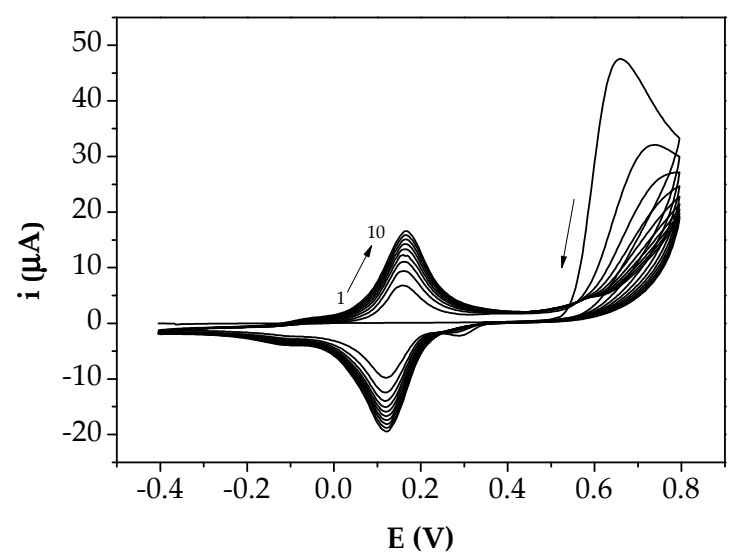

Figure 3. Electropolymerisation of $2.5 \mathrm{mM}$ aniline solution in $50 \mathrm{mM} \mathrm{HClO}_{4}$ at GSPE surface by cyclic voltammetry (potential range: $-400 \mathrm{mV} \rightarrow+800 \mathrm{mV}$; scan rate: $50 \mathrm{mV} / \mathrm{s}$; 10 cycles).

The number of cycles of electropolymerisation was chosen according to the data from the cyclic voltammetry, considering the growth of the faradaic current with each cycle. However, the application of 10 cycles to obtain the PANI/GSPEs was more adequate for the desired purpose, since this gave a more stable signal. When AuNPs were electrodeposited on the PANI/GSPEs by cyclic voltammetry, the current peak dramatically increased (Figure 4). 


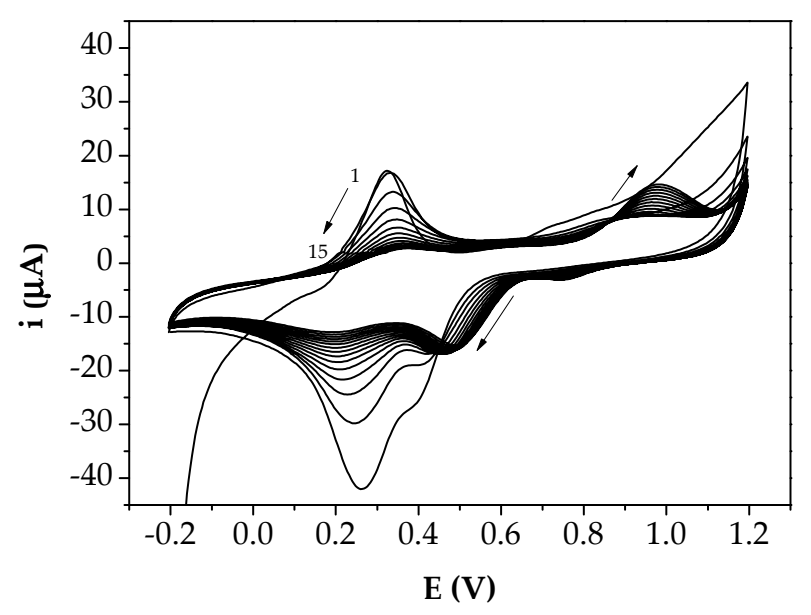

Figure 4. Electrodeposition of gold nanoparticles at PANI/GSPE surface from a $0.5 \mathrm{mM} \mathrm{HAuCl}_{4}$ solution in $0.5 \mathrm{M} \mathrm{H}_{2} \mathrm{SO}_{4}$ by cyclic voltammetry (potential range: $-200 \mathrm{mV} \rightarrow+1200 \mathrm{mV}$; scan rate: $100 \mathrm{mV} / \mathrm{s} ; 15$ cycles).

In particular, the cooperation of PANI and AuNPs in the modified film amplified the peak current and reversibility of redox peaks, which can be related to the larger electroactive surface area of AuNPs/PANI/GSPEs and electrocatalytic behaviour of gold nanoparticles (Figure 5) than PANI/GSPEs.

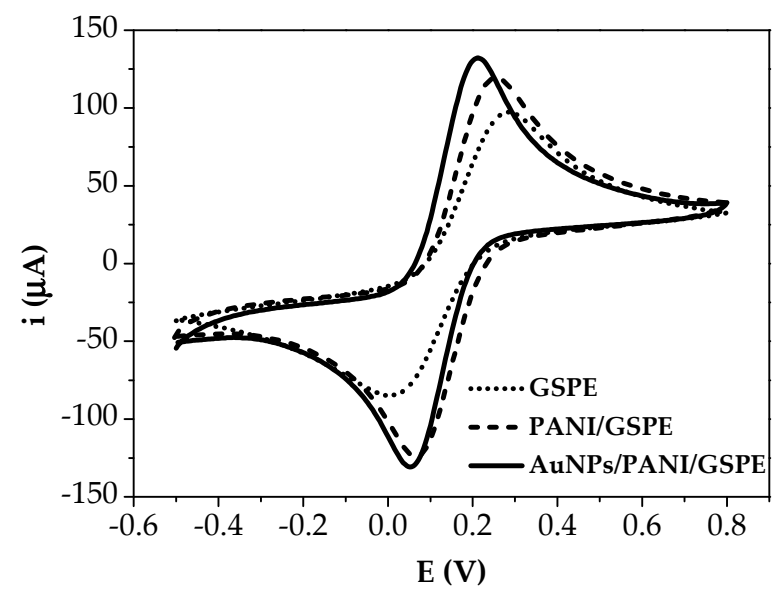

Figure 5. Electrochemical characterisation of modified SPEs by cyclic voltammetry (potential range: $-500 \mathrm{mV} \rightarrow+800 \mathrm{mV}$; scan rate: $150 \mathrm{mV} / \mathrm{s}$ ) by using the $\mathrm{Fe}(\mathrm{CN})_{6}{ }^{4-/ 3-}$ redox couple $(5.0 \mathrm{mM}$ solution in $0.1 \mathrm{KCl}$ ).

AuNPs are excellent electrical conductors; their incorporation in the polymer generated multiple active sites, which facilitated the electron transfer across the PANI matrix during the electrochemical processes.

\subsubsection{Competitive Assay}

In order to develop the competitive aptamer-based assay for profenofos detection, the thiolated DNA capture probe (oligo-SH) was immobilised on modified graphite screen-printed working electrodes, and the hybridisation reaction with the concentration of biotinylated aptamer sequence (apt-BIO) was performed in accordance with previously reported studies $[7,14]$. 
Apt-BIO is functionalised with biotin in $5^{\prime}$ end, in order to interact with streptavidin-alkaline phosphatase enzyme conjugate. The current peak increased linearly with apt-BIO concentration up to $0.50 \mu \mathrm{M}$, where a plateau was reached (Figure 6).

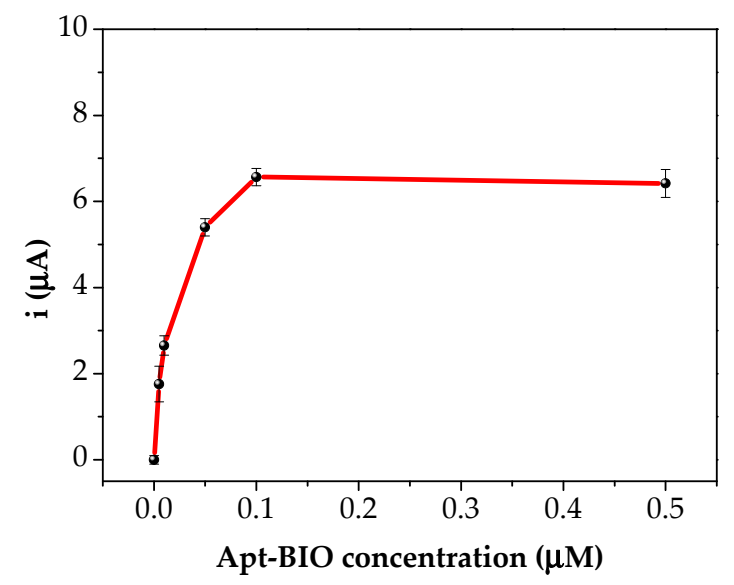

Figure 6. Hybridisation curve between immobilised oligonucleotide sequence $(2.0 \mu \mathrm{M})$ and biotinylated aptamer solution in $0.50 \mathrm{M}$ phosphate buffer, $\mathrm{pH}$ 7.0. Each point was repeated at least five times using different aptasensors.

This behaviour is due to the limited number of biorecognition sites that were bound onto the sensor surfaces. The concentration of $0.50 \mu \mathrm{M}$ apt-BIO was thus used for all experiments involving profenofos, since to perform the competitive assay, it is necessary to work in saturation conditions to obtain the maximum signal value in absence of the analyte.

\subsubsection{Profenofos Detection}

The pesticide detection was performed by competitive assay. In order to check if the pesticide itself, as an organophosphorus compound, could constitute an inhibition element for the phosphatase enzyme used in the labelling step, spectrophotometric measurements were carried out. Absorbance at $405 \mathrm{~nm}$ was collected for biotinylated aptamer sequence, profenofos and enzyme in the presence of $p$-nitrophenyl-phosphate enzymatic substrate. No significantly different values were obtained compared to the ones collected without profenofos, confirming that the pesticide is not interfering with the enzymatic activity (data not shown).

Various profenofos concentrations containing $0.50 \mu \mathrm{M}$ apt-BIO were thus evaluated. A dose-response curve of profenofos was obtained. The signal is reported as $S_{x} / S_{0}$ percent units, that is the percentage of the signal decrease with respect to the blank value. A decrement of the current peak height was recorded by increasing the concentration of the pesticide in the range $0.10-10 \mu \mathrm{M}$ at a fixed concentration of the aptamer sequence (apt-BIO) (Figure 7).

The fitting of experimental data values gives the equation

$$
y=42.2+\frac{127.2}{1+e^{(x+0.3) / 1.7}}
$$

A correlation coefficient $\mathrm{R}^{2}$ of 0.997 was found. The detection limit (DL) was calculated as previously reported by Taylor et al. [23], and a value of $0.27 \mu \mathrm{M}$ was obtained. The reproducibility of the aptasensor was also evaluated by multiple analysis of each standard profenofos solution.

Aptamer cross-reactivity of the proposed aptasensor was investigated in the presence of paraoxon, another OP pesticide. Paraoxon is the active metabolite of parathion, a molecule with a strong insecticidal and acaricidal effect, and the exposure to this molecule produces high mortality [24]. A value of $10 \% \mathrm{~S}_{\mathrm{x}} / \mathrm{S}_{0}$ was observed when $1.0 \mu \mathrm{M}$ of parathion solution was tested. The described 
aptasensor was confirmed as a promising analytical tool for pesticide detection, since the tested concentrations gave an average $0.2 \%$ RSD value for ten repetitions of each standard solution.

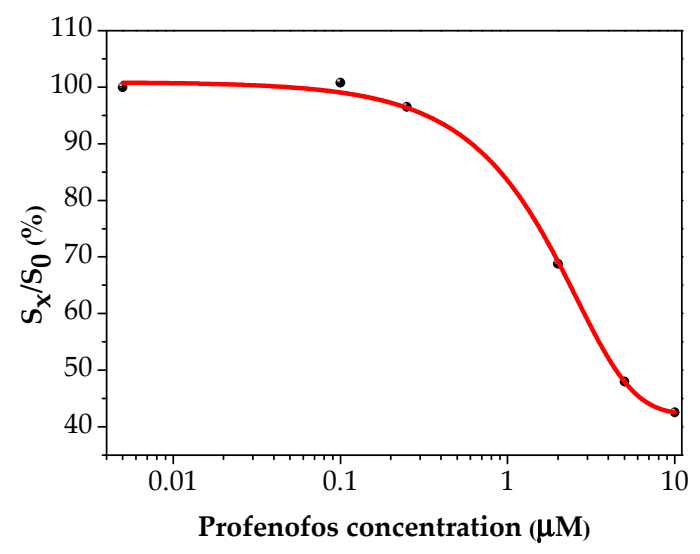

Figure 7. Profenofos dose-response curve. Each point was repeated at least 5 times using different aptasensors. The points correspond to $\% \mathrm{~S}_{\mathrm{x}} / \mathrm{S}_{\mathrm{o}} \pm$ R.S.D. (error bars are smaller than data points).

\subsubsection{Fruit Juice Samples Analysis}

In order to evaluate the practicability of the aptasensor, the preliminary experiments were performed in commercially available pear juice samples were carried out. Profenofos standard solutions were added to the samples after dilution (1:10) in phosphate buffer. The aptasensor response was then determined by DPV measurements, in the same conditions used for the pesticide calibration curve (Figure 8).

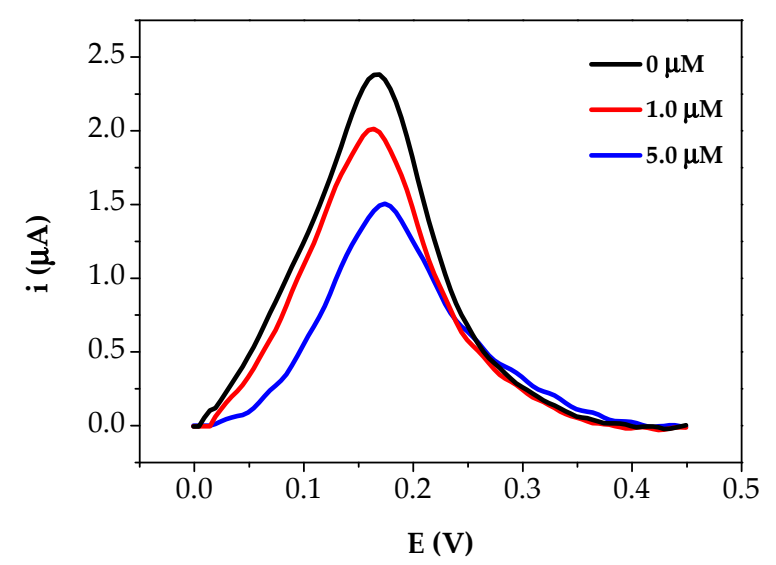

Figure 8. DPV scans of the analysed fruit juice samples spiked with profenofos solution.

The signal was found to decrease with respect to the sample solution by increasing the profenofos spiked concentration in the analysed samples. The profenofos concentration in the pear juice samples was calculated through the obtained calibration curve. A little matrix effect was observed resulting the recovery value. The results obtained for the spiked samples with standard addition of profenofos are shown in Table 2. 
Table 2. Recoveries of pear juice samples spiked with profenofos standard solutions. Each concentration was repeated at least five times using different aptasensors.

\begin{tabular}{ccccc}
\hline Profenofos Spiked $(\mu \mathrm{M})$ & Profenofos Found $(\mu \mathrm{M})$ & Recovery $(\%)$ & Bias $(\%)$ & \% RSD \\
\hline 1.0 & 0.87 & 87 & -13 & 10 \\
3.0 & 2.45 & 82 & -18 & 15 \\
\hline
\end{tabular}

\section{Conclusions}

Affinity-based biosensing can contribute to pesticide detection as a valid and innovative analytical approach. In this work, we developed, for the first time, a simple and cost-effective aptasensor for the direct determination of profenofos pesticide based on a competitive format and disposable screen-printed electrochemical cells. Preliminary experiments were performed with real samples. A dose response curve was obtained between $0.10 \mu \mathrm{M}$ and $10 \mu \mathrm{M}$ with a detection limit of $0.27 \mu \mathrm{M}$. The sensitivity achieved was adequate for the analysis of profenofos in real samples, although the highest level of a pesticide residue that is legally tolerated in or on food depends on the food nature. From the obtained results, this analytical tool has proven itself to be promising for application in real samples analysis, since it involved low amounts of reagents and easy-to-prepare portable aptasensors. All these features make it suitable for the realisation of a commercial kit. This allows in situ analysis that with traditional techniques such as chromatography is not achievable.

Author Contributions: Data curation, O.H.; Funding acquisition, G.M.; Investigation, G.S. and I.B.; Supervision, C.C., R.S. and G.M.; Writing-review \& editing, G.S., I.B., O.H., C.C., R.S. and G.M.

Acknowledgments: Proc. 465571/2014-0, Brasil CNPq: National Institute for Alternative Technologies of Detection, Toxicological Evaluation and Removal of Micropollutants and Radioactives.

Conflicts of Interest: The authors declare no conflict of interest. The founding sponsors had no role in the design of the study; in the collection, analyses, or interpretation of data; in the writing of the manuscript, and in the decision to publish the results.

\section{References}

1. FAO (Food and Agriculture Organization); WHO (World Health Organization). Manual on Development and Use of FAO and WHO Specifications for Pesticides. In FAO Plant Production and Protection Paper; FAO (Food and Agriculture Organization): Roma, Italy; WHO (World Health Organization): Geneva, Switzerland, 2016.

2. Martin, L.J. Pesticide Exposure in Womb Linked to Lower IQ. Available online: https:/ /www.webmd.com/ baby/news / 20110421/pesticide-exposure-in-womb-linked-to-lower-iq\#1 (accessed on 2 May 2018).

3. Verma, N.; Bhardwaj, A. Biosensor Technology for Pesticides-A review. Appl. Biochem. Biotechnol. 2015, 175, 3093-3119. [CrossRef] [PubMed]

4. Aceña, J.; Stampachiacchiere, S.; Pérez, S.; Barceló, D. Advances in liquid chromatography-high-resolution mass spectrometry for quantitative and qualitative environmental analysis. Anal. Bioanal. Chem. 2015, 407, 6289-6299. [CrossRef] [PubMed]

5. Dobrat, W.; Martijn, A. Analysis of Technical and Formulated Pesticides. In CIPAC Handbook; Collaborative International Pesticides Analytical Council: Harpenden, UK, 1998; Volume H, p. 223.

6. Mahajan, R.; Chatterjee, S. A simple HPLC-DAD method for simultaneous detection of two organophosphates, profenofos and fenthion, and validation by soil microcosm experiment. Environ. Monit. Assess. 2018, 190, 327. [CrossRef] [PubMed]

7. Liang, H.C.; Bilon, M.; Hay, M.T. Analytical Methods for Pesticide Residues in the Water Environment. Water Environ. Res. 2015, 87, 1923-1937. [CrossRef] [PubMed]

8. Sassolas, A. Biosensors for Pesticide Detection: New Trends. Am. J. Anal. Chem. 2012, 3, 210-232. [CrossRef]

9. Rapini, R.; Cincinelli, A.; Marrazza, G. Acetamiprid multidetection by disposable electrochemical DNA aptasensor. Talanta 2016, 161, 15-21. [CrossRef] [PubMed]

10. Rapini, R.; Marrazza, G. Electrochemical aptasensors for contaminants detection in food and environment: Recent advances. Bioelectrochemistry 2017, 118, 47-61. [CrossRef] [PubMed] 
11. Wang, P.; Wan, Y.; Ali, A.; Deng, S.; Su, Y.; Fan, C.; Yang, S. Aptamer-wrapped gold nanoparticles for the colorimetric detection of omethoate. Sci. China Chem. 2016, 59, 237-242. [CrossRef]

12. Bala, R.; Dhingra, S.; Kumar, M.; Bansal, K.; Mittal, S.; Sharma, R.K.; Wangoo, N. Detection of organophosphorus pesticide-Malathion in environmental samples using peptide and aptamer based nanoprobes. Chem. Eng. J. 2017, 311, 111-116. [CrossRef]

13. Xu, G.; Huo, D.; Hou, C.; Zhao, Y.; Bao, J.; Yang, M.; Fa, H. A regenerative and selective electrochemical aptasensor based on copper oxide nanoflowers-single walled carbon nanotubes nanocomposite for chlorpyrifos detection. Talanta 2018, 178, 1046-1052. [CrossRef] [PubMed]

14. Dong, J.; Gao, N.; Peng, Y.; Guo, C.; Lv, Z.; Wang, Y.; Zhou, C.; Ning, B.; Liu, M.; Gao, Z. Surface plasmon resonance sensor for profenofos detection using molecularly imprinted thin film as recognition element. Food Control 2012, 25, 543-549. [CrossRef]

15. Shrivastav, A.M.; Usha, S.P.; Gupta, B.D. Fiber optic profenofos sensor based on surface plasmon resonance technique and molecular imprinting. Biosens. Bioelectron. 2016, 79, 150-157. [CrossRef] [PubMed]

16. Shi, H.; Zhao, G.; Cao, T.; Liu, M.; Guan, C.; Huang, X.; Zhu, Z.; Yang, N.; Williams, O.A. Selective and visible-light-driven profenofos sensing with calixarene receptors on $\mathrm{TiO}_{2}$ nanotube film electrodes. Electrochem. Commun. 2012, 19, 111-114. [CrossRef]

17. Wang, L.; Liu, X.; Zhang, Q.; Zhang, C.; Liu, Y.; Tu, K.; Tu, J. Selection of DNA aptamers that bind to four organophosphorus pesticides. Biotechnol. Lett. 2012, 34, 869-874. [CrossRef] [PubMed]

18. The Mfold Web Server. Available online: http://unafold.rna.albany.edu/?q=mfold/DNA-Folding-Form (accessed on 2 May 2018).

19. Saberi, R.-S.; Shahrokhian, S.; Marrazza, G. Amplified Electrochemical DNA Sensor Based on Polyaniline Film and Gold Nanoparticles. Electroanalysis 2013, 25, 1373-1380. [CrossRef]

20. Ravalli, A.; Rossi, C.; Marrazza, G. Bio-inspired fish robot based on chemical sensors. Sens. Actuators B Chem. 2017, 239, 325-329. [CrossRef]

21. Lucarelli, F.; Marrazza, G.; Mascini, M. Dendritic-like streptavidin/alkaline phosphatase nanoarchitectures for amplified electrochemical sensing of DNA sequences. Langmuir 2006, 22, 4305-4309. [CrossRef] [PubMed]

22. Centi, S.; Silva, E.; Laschi, S.; Palchetti, I.; Mascini, M. Polychlorinated biphenyls (PCBs) detection in milk samples by an electrochemical magneto-immunosensor (EMI) coupled to solid-phase extraction (SPE) and disposable low-density arrays. Anal. Chim. Acta 2007, 594, 9-16. [CrossRef] [PubMed]

23. Taylor, J.; Picelli, G.; Harrison, D.J. An evaluation of the detection limits possible for competitive capillary electrophoretic immunoassays. Electrophoresis 2001, 22, 3699-3708. [CrossRef]

24. Deshpande, L.S.; Carter, D.S.; Phillips, K.F.; Blair, R.E.; De Lorenzo, R.J. Development of status epilepticus, sustained calcium elevations and neuronal injury in a rat survival model of lethal paraoxon intoxication. Neurotoxicology 2014, 44, 17-26. [CrossRef] [PubMed] 